\title{
Aplicação de técnicas de redes neurais e modelagem atmosférica para elaboração de previsões de vazão na Bacia do Rio Grande (MG)
}

\author{
Application of neural networks techniques and atmospheric modeling \\ to elaborate inflow forecasts in the Rio Grande Basin (MG), Brazil
}

Talita Lopes Dias', Marcio Cataldi², Vitor Hugo Ferreira²

$\square$

\begin{abstract}
RESUMO
Neste estudo foi proposta a elaboração de um modelo de previsão de vazões no horizonte de dez dias para a Usina Hidrelétrica de Furnas, localizada na Bacia do Rio Grande, Minas Gerais, a partir da aplicação de redes neurais artificiais (RNA), informações de vazão natural e precipitação observada e prevista. O modelo foi desenvolvido utilizando o software Matlab ${ }^{\circledR}$ Neural Network Toolbox. Escolheu-se uma rede neural do tipo perceptron multicamadas (MLP), treinada com algoritmo supervisionado de retropropagação LevenbergMarquardt. As previsões de precipitação foram obtidas a partir do modelo ETA/ Centro de Previsão do Tempo e Estudos Climáticos (CPTEC), e utilizadas com e sem tratamento matemático. Foram realizados três experimentos, dividindose o histórico de dados em três períodos, sendo o primeiro para a calibração do modelo, o segundo para a validação e o terceiro para os testes. Em cada experimento foi variado o conjunto de dados de entrada, sendo utilizada, no primeiro experimento, somente a vazão passada para prever os dez dias de vazão futura. No segundo foi adicionada a precipitação observada e, no terceiro, a previsão de precipitação. Os resultados da modelagem chuva-vazão obtidos com a previsão de precipitaçãodo modelo ETA não apresentaram melhorias estatísticas em comparação com os experimentos que só utilizaram informações passadas. No entanto, quando se utilizou a previsão de precipitação corrigida matematicamente, observou-se uma melhora sensível tanto nos índices estatísticos quanto na representação da previsão simulada no hidrograma, ficando o desempenho da modelagem proposta neste estudo semelhante à encontrada em modelos conceituais do tipo chuva-vazão.
\end{abstract}

Palavras-chave: modelo ETA; perceptron multicamadas; modelagem chuva-vazão.

\begin{abstract}
The purpose of this study was to elaborate a ten-year runoff forecast model for the Furnas hydroelectric plant. The facility is located in the Rio Grande Basin in the state of Minas Gerais, Brazil. Artificial neural networks were used to determine natural flow as well as observed and predicted precipitation. The model was created using the Matlab ${ }^{\circledR}$ Neural Network Toolbox software, and the multi-layers perceptron (MLP) was trained with supervised learning algorithm Levenberg-Marquardt. Precipitation forecasts derived from ETA/ Centro de Previsão do Tempo e Estudos Climáticos (CPTEC) model, and both raw and mathematical adjusted data were used. Historical data was separated in three different periods in order to calibrate, validate and test the model. The first share was used for calibration, the second portion was used for validation and the third one to test the model. In each experiment the input data was modified; thus, in the first experiment, to forecast the ten day runoff, only the past runoff data was considered. In the second experiment, observed precipitation was added; and in the third one, the forecast precipitation was added. The rainfall-runoff modeling results did not show any significant improvement in the statistics when ETA input data is compared with the experiments that only used past information as input. Nevertheless, when forecast precipitation was used with mathematical adjustment, a mild improvement was shown for the statistics index and for the forecast hydrogram simulation. As a result, the modeling performance proposed in this study is similar to that found in conceptual models of rainfall-runoff type.
\end{abstract}

Keywords: ETA model; multi-layer-perceptron; inflow simulation. 口-

\section{INTRODUÇÃO}

A previsão de vazões é de grande importância em todo o mundo, e, em especial, no Brasil, pois possui grande percentual de rios e mananciais. A utilização desses dados serve para a irrigação, o fornecimento

de água à população em quantidade compatível com suas necessidades, o turismo, a navegação e a geração de energia elétrica.

Um dos principais insumos para o conhecimento da variabilidade das vazões é a informação da precipitação que ocorreu e que ainda irá

口-

'Mestre pela Universidade Federal do Rio de Janeiro (UFRJ) - Rio de Janeiro (RJ), Brasil.

2Doutor pela UFRJ - Rio de Janeiro (RJ), Brasil.

Endereço para correspondência: Marcio Cataldi - Rua Passo da Pátria, 156 - Sala 304 Bloco E - São Domingos - CEP: $24210-240$ - Niterói (RJ), Brasil - E-mail: mcataldi@id.uff.br Recebido: 21/12/15 - Aceito: 02/06/16 - Reg. ABES: 158015 
ocorrer em uma determinada bacia hidrográfica. Dessa forma, os avanços no conhecimento da previsão de vazões vêm contribuindo também para que o homem aprimore seus conhecimentos sobre o ciclo hidrológico (FERNÁNDEZ; VENTURA DE SÁ; CATALDI, 2015).

Nas últimas décadas, a evolução de diferentes tecnologias de modelagem proporcionou uma melhor reprodução dos fenômenos naturais, dando ao homem a oportunidade de compreender os processos físicos e biológicos. Em relação a esses fatos, destacam-se os avanços na modelagem numérica dos processos físicos inerentes à previsão de tempo e clima. Para a hidrologia existe um pleno potencial de utilização dessas estimativas de precipitação, na área de previsão de vazões, e no aprimoramento do conhecimento sobre os diferentes fenômenos naturais que constituem o ciclo hidrológico (CATALDI et al., 2007a).

As hidrelétricas são as principais fontes de energia elétrica da matriz energética do país. Esse fato implica na necessidade de previsões de vazão natural com qualidade, visto que são de extrema importância para o planejamento e operação do Sistema Interligado Nacional (SIN).

Em 2004, o Operador Nacional do Sistema Elétrico (ONS) contratou uma concorrência envolvendo diversos tipos de modelagem chuva-vazão, com incorporação de precipitação tanto observada quanto prevista, para três bacias do SIN. O estudo obteve previsões de vazão com erros menores do que as obtidas com a metodologia até então utilizada, que não considerava nenhuma informação de precipitação (GUILHON; ROCHA; MOREIRA, 2007). Foram ainda desenvolvidas pelo ONS metodologias para a previsão de vazões na cabeceira do Rio São Francisco (GOMES, 2006), que utilizou redes neurais artificiais (RNA), e para a Bacia do Alto/Médio Grande, utilizando o modelo conceitual Soil Moisture Accounting Procedure (SMAP) (SATURNINO BRAGA; CATALDI; CRETON DE OLIVEIRA, 2009). Ambas metodologias apresentaram melhores resultados do que o modelo anteriormente utilizado pelo ONS, que considerava somente as vazões passadas como insumo.

Nos últimos anos, a aplicação da metodologia de redes neurais vem sendo objetivo de crescentes pesquisas, servindo como valiosa ferramenta para diversas aplicações. Os empregos dessas pesquisas ganharam espaço também na área de recursos hídricos, onde, na maioria das vezes, a utilização da técnica na previsão de vazões apresentou resultados compatíveis ou superiores às técnicas tradicionais (EVSUKOFF; CATALDI; DE LIMA, 2012).

Segundo Guilhon (2002), a introdução de informações de precipitação observada ao modelo heurístico, que se baseia na intuição e nas circunstâncias a fim de gerar conhecimento novo, trouxe um ganho qualitativo paras as previsões de vazões médias semanais à Usina Hidrelétrica (UHE) de Foz do Areia e, provavelmente, trará para outras bacias que obtiverem uma boa correlação entre as variáveis.

Gomes (2006) calibrou dois modelos de redes neurais, uma multi-layer perceptrons (MLP) com algoritmo de backpropagation, que são redes que possuem uma ou mais camadas escondidas de neurônios, e a outra uma rede do tipo non-linear sigmoidal regression blocks networks (NSRBN), que são redes compostas por blocos de regressões sigmoides não lineares. As previsões foram realizadas para a UHE Três Marias, na Bacia do Rio São Francisco, em um horizonte de 12 dias, utilizando informações observadas de postos pluviométricos, fluviométricos e de vazão natural. Nesse estudo, a autora verificou que as redes neurais possibilitaram a obtenção da previsão de vazões com desempenho superiores às obtidas nos modelos estatísticos tanto para horizontes diários como semanais.

Cataldi et al. (2007b) realizaram um estudo aplicando técnicas de mineração de dados e de redes neurais com treinamento bayesiano, para o balizamento da escolha da melhor previsão de vazões naturais do sistema de modelos estocásticos PREVIVAZ. Foram utilizadas informações de precipitação observada e prevista, além das vazões naturais verificadas nos últimos dias que antecederam a previsão. $O$ estudo foi realizado para os aproveitamentos hidrelétricos de Foz do Areia e Salto Santiago na Bacia do Rio Iguaçu, para um horizonte de dez dias à frente. Os resultados obtidos mostraram que essa poderia ser uma solução simples e eficaz para a diminuição dos erros de previsão em horizonte semanal de vazão natural na bacia.

Recentemente, na literatura internacional, algumas publicações científicas vêm utilizando os modelos de RNA para a previsão de vazões, em diferentes horizontes temporais e com distintas configurações de dados de entrada (MAIER \& DANDY, 2000; BAZARTSEREN; HILDEBRANDT; HOLZ, 2003; GOUTE, 1997; GYON \& ELISSEFF, 2003).

Neste estudo, foi elaborado um modelo de previsão de vazão para um horizonte de dez dias à frente, para o trecho da Bacia do Rio Grande incremental da UHE Furnas. Para tal foram utilizadas RNA, incluindo informações de vazão e precipitação observadas, precipitação prevista e prevista corrigida. $\mathrm{O}$ trecho incremental engloba os postos fluviométricos de controle de Paraguaçu, Porto dos Buenos, a UHE Funil e a UHE Furnas.

\section{METODOLOGIA}

\section{Modelo ETA e previsão de precipitação}

O modelo ETA é utilizado operacionalmente para produzir previsões de tempo na América do Sul desde 1996 no Centro de Previsão do Tempo e Estudos Climáticos (CPTEC), ligado ao Instituto de Pesquisas Espaciais (INPE). Ele é um modelo numérico regional de previsão do tempo, baseado no método de diferenças finitas, sendo discretizado em ponto de grade, no qual a coordenada vertical se baseia em pressão, o que torna a superfície basicamente horizontal, minimizando os cálculos das derivadas horizontais nas regiões montanhosas. A condição de contorno lateral é prescrita em uma fileira, sem necessidade 
de relaxação da lateral, sendo proveniente das simulações do modelo global do CPTEC. Como condição de contorno inferior é utilizada a temperatura da superfície do mar diária e a umidade do solo mensal climatológica. As variáveis prognósticas são: temperatura, umidade, vento horizontal, pressão à superfície, energia cinética turbulenta, umidade e temperatura do solo e água líquida ou gelo das nuvens (MESINGER et al., 1988; BLACK, 1994).

O desempenho das previsões do modelo numérico ETA foi avaliado por Cataldi et al. (2007a). Esse estudo teve como propósito verificar o desempenho quantitativo da previsão de precipitação do modelo ETA, no período de 1996 a 2003, utilizada como insumo no processamento de modelos de prognóstico de vazões para as bacias dos rios Paranaíba, Paraná e Iguaçu, para o horizonte de dez dias à frente. Foi verificado que a previsão de precipitação agrupada em períodos superiores a um dia apresenta resultados mais semelhantes aos valores observados. Nos casos onde a precipitação observada foi superior a $10 \mathrm{~mm}$, o modelo apresenta uma tendência em superestimar as precipitações observadas. Em poucos casos no período estudado, as previsões superaram em mais de $30 \mathrm{~mm}$ os valores observados. Eventos de escala inferior à mesoescala não são capturados corretamente durante o período de integração do modelo. Contudo, essa previsão de precipitação proveniente do modelo ETA é potencialmente útil como subsídio para o processo de predição de vazões naturais, sendo necessário, no entanto, para algumas regiões do país, um tratamento estatístico de algumas variáveis prognósticas, visando à identificação e remoção de possíveis erros sistemáticos.

A distribuição espacial da chuva média prevista em pontos de grade do modelo ETA possui uma resolução espacial horizontal de 40 x $40 \mathrm{~km}$. Foi utilizado também o software Matlab ${ }^{\circledR}$ para o cálculo da chuva média algébrica somente para os pontos de grade dentro do contorno da bacia.

\section{Configuração e especificação da rede neural}

A rede neural utilizada neste trabalho foi criada no software Matlab $^{\star}$ Toolbox Redes Neurais, na versão 7.6 (R2008a). Foi escolhida uma RNA do tipo múltiplas camadas de perceptrons (MLP), exemplificada na Figura 1, treinada com algoritmo de aprendizado supervisionado de retropropagação Levenberg-Marquardt, semelhante à utilizada por Gomes (2006). A escolha dessa rede foi baseada no bom desempenho apresentado no trabalho desse autor, no qual foi utilizada para um problema semelhante ao abordado neste artigo em uma bacia hidrográfica geograficamente próxima à Bacia do Rio Grande, a cabeceira do Rio São Francisco.

Os dados de entrada são as variáveis preditoras, ou seja, aquelas que o modelo de RNA irá utilizar para prever as variáveis meta, ou alvo. Posteriormente, utilizou-se uma análise das componentes principais (ACP), na qual foi possível retirar os elementos que contribuíam com menos de $0,1 \%$ da variabilidade dos dados meta. Esse método estatístico é usado quando se pretende reduzir, retirar sobreposições e extrair dos dados originais um conjunto pequeno de variáveis contendo a máxima informação possível a partir de combinações lineares. Essa abordagem é importante para se retirar possíveis dados e/ou combinações lineares que possam trazer ruído para o aprendizado da $\mathrm{RN}$ e, portanto, comprometer as relações de causa e efeito, fundamentais para o desempenho da $\mathrm{RN}$, já que esse tipo de modelagem não possui em sua formulação matemática nenhuma informação dos processos físicos que relacionam as variáveis de chuva e vazão.

A estrutura desse modelo é constituída por uma camada escondida de neurônios entre as camadas de entrada e saída. Na camada escondida, a função de ativação utilizada foi a tangente sigmoidal; e na camada de saída, a função linear. A função trainlm faz referência ao treinamento Levenberg-Marquardt e foi utilizada para que o treinamento obtivesse maior velocidade na convergência. $O$ método de Levenberg-Marquardt é considerado, na prática, bastante robusto, já que utiliza a combinação ponderada entre o passo do método de Gauss-Newton e a direção de descida mais íngreme (HEATH, 2002).

Uma das propriedades mais importantes de uma rede neural é a capacidade de aprendizado e, com isso, aprimorar o seu desempenho. Isso ocorre através de um processo iterativo de ajustes aplicados aos seus pesos, conhecido como treinamento. Essa capacidade de aprendizado ocorre a partir do gradiente descendente que é efetuado pelo algoritmo de retropropagação. $\mathrm{O}$ objetivo do gradiente descendente é buscar o mínimo local através de ajustes nos pesos sinápticos por um valor que é proporcional ao sentido contrário da derivada do erro fornecido pelo neurônio, em relação ao valor do peso. O termo retropropagação está relacionado à proliferação recursiva dos erros. Portanto, o treinamento pode ser entendido da seguinte forma: inicialmente propagam-se os sinais no sentido progressivo (da camada de entrada para a de saída). Em seguida, são calculados os erros propagados recursivamente (da camada de saída para a de entrada) através da rede, determinando-se as derivadas da função erro. Finalmente, essas derivadas são utilizadas para realizar o ajuste dos pesos (VALENÇA, 2005).

Foram feitos diversos testes com de um até seis neurônios na camada escondida, descartando a utilização de modelos com um, dois e seis neurônios, já que nessas configurações o desempenho em termos de precisão das previsões foi inferior ao obtido com três, quatro e cinco neurônios.

Nos testes preliminares, observou-se que a convergência ocorria normalmente entre 5 e 20 iterações. Ou seja, após a confluência, o erro tende a ser assintótico, não sendo necessárias mais iterações. Dessa forma, o número máximo de iterações foi fixado em cem. Além disso, o treinamento da RNA utilizado neste estudo foi implementado utilizando o algoritmo de Levenberg-Marquardt (HAYKIN, 2008), atendendo a três critérios de parada: erro médio quadrático durante o treinamento menor que 1e-10; parâmetro de regularização do algoritmo de 
Levenberg-Marquardt superior a 1e+10; quando o desempenho para o conjunto de validação for reduzido por até 5 iterações consecutivas durante a validação possuir um número de falhas maior do que 5 .

Como no tipo de treinamento empregado na RN utilizada neste estudo existe um sorteio inicial de pesos aleatórios, os resultados para uma mesma configuração e com os mesmos valores de parâmetros e hiperparâmetros acaba gerando resultados ligeiramente diferentes. Dessa forma, foram realizadas sempre dez simulações para cada experimento tanto na fase de busca da melhor configuração da $\mathrm{RN}$ quanto nas simulações finais. Com isso, foram feitas médias das simulações nos períodos de treinamento, validação e teste, para os cálculos dos erros absolutos, relativos e hidrogramas utilizados na comparação dos experimentos.

Como o histórico disponível de todos os dados de entrada, concomitantemente, era de 1996 a 2003, foi utilizado, em todos os experimentos, o período de 1996 a 2000 para treinamento da RN, o de 2001 para a validação e os de 2002 e 2003 para os de testes. O ano de 2001 foi utilizado na validação principalmente pelo fato de ter sido um ano de baixas afluências na bacia em estudo. Os modelos de previsão de vazão utilizando RN tendem a ser bastante sensíveis à variação da precipitação, sendo capazes de, facilmente, reproduzir grandes períodos de cheia. No entanto, esses modelos, em geral, tendem a ter dificuldade para reproduzir períodos de recessão e situações onde o escoamento da bacia é próximo ao seu escoamento de base (GOMES, 2006; CATALDI et al., 2007b). Como o ajuste dos parâmetros da RN também leva em consideração o período de validação, a ideia foi utilizar somente o ano de 2001 para a validação, objetivando que a $\mathrm{RN}$ apresentasse melhores resultados na representação de períodos de baixa afluência, próximas ao escoamento de base.

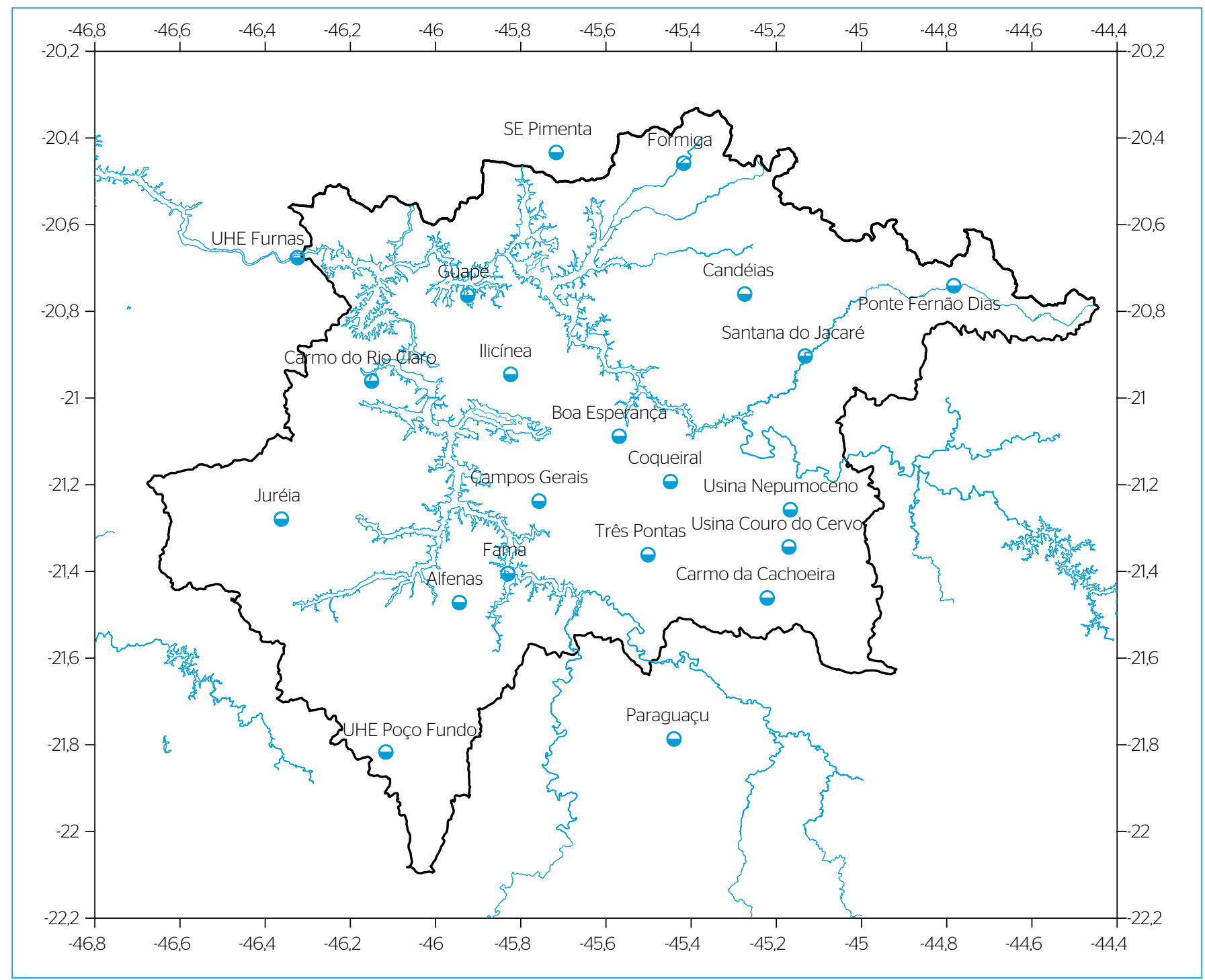

Figura 1 - Distribuição espacial dos postos pluviométricos utilizados na modelagem. 


\section{Dados e região de estudo}

A RN foi estruturada com intuito de prever a vazão no trecho incremental da UHE Furnas na Bacia do Rio Grande, situada no estado de Minas Gerais, para dez dias a frente. A UHE Furnas é uma das principais do país, possuindo um dos maiores reservatórios de regulação do subsistema sudeste, sendo, portanto, o planejamento de sua operação de grande importância para operação de todo o SIN. A região da bacia incremental possui em torno de $20.501 \mathrm{~km}^{2}$. A previsão de vazões para a usina apresenta um complicador a mais, já que a vazão incremental do rio principal é composta por três afluentes, com tempos de viagem diferentes, que foram considerados no cálculo da vazão incremental utilizada neste estudo, conforme metodologia descrita em Saturnino Braga, Cataldi e Creton de Oliveira (2009). Nesse trabalho, o objeto das previsões foi a primeira semana operativa do sistema elétrico brasileiro, que começa no primeiro sábado seguinte à realização da previsão e vai até a próxima sexta-feira, atendendo ao programa mensal de operação (PMO).

Os dados históricos utilizados no modelo de RN foram disponibilizados pelo ONS. As variáveis foram a vazão natural incremental à UHE Furnas, a média da precipitação observada nos postos pluviométricos da região, listados na Tabela 1, a previsão de precipitação do modelo ETA dez dias a frente, sempre iniciada às quartas-feiras, e essa mesma previsão de precipitação corrigida. No caso da precipitação observada, os dados faltantes foram completados pela média dos vizinhos mais próximos. Para o cálculo da média de chuva na bacia, tanto nos dados observados quanto nos previstos, foi utilizada a média algébrica. A distribuição espacial dos postos ao longo da bacia pode ser visualizada na Figura 1, juntamente com a sua hidrografia de primeira ordem.

A precipitação média desse trecho da Bacia do Rio Grande possui uma sazonalidade marcante, tendo os maiores totais de precipitação observados durante o verão, influenciados principalmente pela Zona de Convergência do Atlântico Sul (ZCAS) e pela passagem de frentes frias. Nos meses de transição (primavera e outono), um número menor de sistemas frontais atinge essa bacia, mas geralmente sem suporte de umidade da região Amazônica, o que leva a totais pluviométricos inferiores aos do verão. No inverno, a maior parte dos transientes se desloca somente pelas regiões litorâneas, com totais médios de precipitação muito baixos durante esse período do ano (OLIVEIRA; CATALDI; TORRES JÚNIOR, 2008).

\section{Tratamento da previsão de precipitação}

Conforme mencionado anteriormente, para uma melhor utilização da previsão de precipitação em modelos do tipo chuva-vazão, é necessária a identificação e posterior remoção de erros sistemáticos, que possam ser tratados estatisticamente. Desse modo, foi desenvolvida uma metodologia para a correção da previsão de chuva do modelo ETA, visando a sua utilização no ONS em modelos de previsão de vazões com uso de informação de precipitação, que até então eram utilizados para as bacias dos rios Iguaçu, Uruguai, Paraná, Grande, Paranaíba e São Francisco. Essa correção ocorreu através da utilização de um treinamento bayesiano para um problema de aproximação funcional, utilizando MLPs com uma única camada escondida e uma única saída linear. Foram treinadas RNAs distintas para cada bacia e para que fossem determinados períodos do ano, com o intuito de capturar os possíveis padrões de erro da projeção de precipitação, associados aos diferentes sistemas sinóticos que atuam ao longo do ano em cada região do país. Para realizar a correção da previsão de precipitação foram utilizadas outras variáveis prognósticas do modelo ETA, que notoriamente possuem um melhor desempenho na modelagem numérica do que a previsão de precipitação, que é uma variável extremamente dependente de esquemas paramétricos. Para isso, foram utilizadas para previsões num horizonte de dez dias a frente, realizadas sempre às quartas-feiras, no período de 1993 a 2003.

O dia da semana foi escolhido propositalmente para fins comparativos com a semana operativa do SIN. Considerando as previsões médias de precipitação para cada bacia, o modelo corretor obteve desempenho

Tabela 1 - Listagem dos postos pluviométricos utilizados para o cálculo da chuva média.

\begin{tabular}{|c|c|c|c|}
\hline Código & Posto & Longitude & Latitude \\
\hline 2145042 & Alfenas & -45.94417 & -21.47190 \\
\hline 2145030 & Boa Esperança & -45.56889 & -21.08810 \\
\hline 2145041 & Campos Gerais & -45.75722 & -21.23780 \\
\hline 2045020 & Candéias & -45.27417 & -20.76000 \\
\hline 2145044 & Carmo da Cachoeira & -45.22139 & -21.46110 \\
\hline 2046028 & Carmo do Rio Claro & -46.15000 & -20.96080 \\
\hline 2145032 & Coqueiral & -45.44861 & -21.19280 \\
\hline 2145047 & Fama & -45.83028 & -21.40500 \\
\hline 2045021 & Formiga & -45.41750 & -20.45810 \\
\hline 2045028 & Guapé & -45.92472 & -20.76310 \\
\hline 2045026 & llicínea & -45.82361 & -20.94530 \\
\hline 2146027 & Juréia & -46.36194 & -21.27920 \\
\hline 2145022 & Paraguaçu & -45.44028 & -21.78640 \\
\hline 2044027 & Ponte Fernão Dias & -44.78333 & -20.74080 \\
\hline 2045004 & Santana do Jacaré & -45.13222 & -20.90310 \\
\hline 2045031 & SE Pimenta & -45.71667 & -20.43330 \\
\hline 2145043 & Três Pontas & -45.50111 & -21.36140 \\
\hline 2046027 & UHE Furnas & -46.32361 & -20.67580 \\
\hline 2146084 & UHE Poço Fundo & -46.11667 & -21.81670 \\
\hline 2145007 & Usina Couro do Cervo & -45.17028 & -21.34360 \\
\hline 2145021 & Usina Nepomuceno & -45.16722 & -21.25750 \\
\hline
\end{tabular}

Fonte: HIDROWEB (2016). 
superior em relação à projeção do modelo ETA. Algumas variáveis meteorológicas apresentaram destaque em relação à sua pertinência e ao número de vezes em que eram selecionadas pelo modelo de $\mathrm{RN}-\mathrm{a}$ saber: fluxo de calor latente médio na superfície; umidade específica no nível de $1.000 \mathrm{hPa}$; temperatura do ponto de orvalho a $2 \mathrm{~m}$; temperatura do ar a $2 \mathrm{~m}$; pressão atmosférica ao nível do mar; componente zonal do vento no nível de $850 \mathrm{hPa}$. Porém, nem sempre uma variável considerada relevante para algumas bacias e em um determinado período do ano também era para outras em períodos diferentes. Esse fato mostra a complexidade associada à elaboração de correções nas previsões de precipitação obtidas a partir de modelagem matemática, tendo em vista que a atmosfera é um sistema intrinsecamente não linear e caótico, e que a formulação contida nas parametrizações responsáveis pela transformação de vapor d’água em água líquida e, posteriormente, em precipitação ainda necessitam de inúmeras melhorias. Mesmo assim, os resultados apresentados neste estudo foram bastante promissores, diminuindo consideravelmente alguns padrões de erros sistemáticos da previsão de precipitação do modelo ETA — principalmente durante o verão nas bacias da região sudeste, e particularmente em regiões de fortes gradientes topográficos.

\section{Experimentos realizados}

Neste trabalho foram feitos três experimentos distintos para avaliar o desempenho da RNA com insumos diferentes.

\section{Experimento 1}

A ideia principal do experimento 1 foi de verificar os resultados da rede utilizando somente dados de vazão como entrada da rede, e avaliando como seria possível prever as vazões futuras a partir desse conjunto de dados. Para isso, foram utilizados cinco dias de vazão passada para prever dez de vazão futura. A série de dados foi separada de modo que o dia ( $t-1)$ de vazão passada seria sempre uma terça-feira, o dia (t-2) sempre segunda-feira, e assim por diante até $(\mathrm{t}-5)$. O mesmo foi feito para os dez dias de vazão futura com $(\mathrm{t})$ sempre às quartas-feiras. O período de cinco dias de vazões passadas foi escolhido de forma arbitrária. O tempo de viagem da vazão das usinas e postos fluviométricos de montante é inferior a um dia, o que não justifica uma quantidade de dias superior para tentar explicar as vazões futuras.

\section{Experimento 2}

No experimento 2 os dados de entrada foram rearranjados com os mesmos cinco dias de vazão passada e adicionados mais cinco dias de precipitação observada; porém, com uma diferença na disponibilização dos dados. O primeiro dia de defasagem (t-1), somente para os dados de precipitação seriam sempre as quartas-feiras, o dia (t-2) sempre as terças-feiras, e assim por diante. O objetivo dessa defasagem foi minimizar as diferenças nos horários das medições da variável vazão, que normalmente são valores médios diários, e os medidos de precipitação que ocorrem a $10 \mathrm{Z}$ ou 12Z (7 ou 9 horas no horário de Brasília). Os dados de meta foram os mesmos do experimento 1 e de todos os outros experimentos, ou seja, com dez dias de vazão futura. O objetivo desse experimento foi ver se a inclusão da precipitação observada, junto com as vazões passadas, contribuía de alguma maneira para explicar as vazões futuras.

\section{Experimento 3}

No experimento 3 foram feitos diversos testes no tempo de defasagem das vazões e das precipitações passadas e também nos dados de futura, inseridos como dado de entrada da rede, para aproveitar a configuração que nos levasse aos menores erros. Assim, foram escolhidos como dados de entrada da rede três dias de vazão passada - com ( $\mathrm{t}-1)$ às terças-feiras, ( $\mathrm{t}-2)$ às segundas-feiras e $(\mathrm{t}-3)$ aos domingos - , um dia de precipitação passada com ( $\mathrm{t}$-1) às quartas-feiras, e oito dias de previsão de precipitação - com $(t+1)$ às quintas-feiras, $(t+2)$ às sextas-feiras, $\mathrm{e}$ assim por diante. Esse experimento foi dividido em três seguimentos (3A, 3B e 3C), nos quais foram diferenciados somente os oito dias de precipitação no período de teste da rede.

No experimento 3A utilizou-se a precipitação observada no lugar da precipitação prevista. A ideia desse experimento foi avaliar, a partir da melhor configuração de dados possível dentre as pesquisadas, qual seria o erro da $\mathrm{RN}$ em prever as vazões futuras, utilizando como variável preditora a melhor previsão de precipitação. Essa melhor previsão de precipitação, que chamaremos de "previsão perfeita", é exatamente a precipitação observada no lugar da prevista — ou seja, a precipitação observada como se fosse a prevista. Dessa forma, nesse experimento o erro que será introduzido nas simulações devido à previsão de precipitação será o menor possível.

No experimento 3B optou-se pela previsão de chuva obtida diretamente das simulações do modelo ETA; e no experimento 3C foi usada a previsão de chuva do modelo ETA após processamento a partir da aplicação da correção do modelo de redes neurais.

\section{RESULTADOS}

Os erros absolutos médios (EAM) e os erros relativos médios (ERM) podem dar uma ideia geral, estatística, dos experimentos efetuados. Na Tabela 2 pode ser observado que o experimento 3A, como esperado, obteve o menor percentual de erro relativo com $13,3 \%$, e que os experimentos 1 e 2 obtiveram 23,0 e 23,1\%, respectivamente. A incorporação da informação de previsão de chuva nos experimentos $3 \mathrm{~B}$ e 3C apresentaram resultados interessantes, já que o desvio do experimento 3B (somente com a previsão bruta do modelo ETA) foi maior do que os experimentos 1 e 2, que levaram em consideração somente 
informações de dados passados. Porém, com a correção da chuva, o erro relativo médio passa a apresentar um desvio de $17,2 \%$, menor do que os experimentos 1 e 2 .

Os EAM vistos na Tabela 3 seguiram as mesmas tendências observadas na tabela dos ERM (Tabela 2).

É importante ressaltar que a melhoria significativa dos resultados do experimento $3 \mathrm{C}$ em relação ao $3 \mathrm{~B}$ esteve muito relacionada com o processo de tratamento das previsões de precipitação utilizando-se redes neurais, como pode se observar na Figura 2. Nessa figura é visto que, para o trecho incremental da usina de Furnas, na Bacia do Rio Grande, nos anos de 2002 e 2003, o tratamento da previsão de

Tabela 2 - Erros relativos médios na semana operativa (\%) no período de (2002 a 2003).

\begin{tabular}{l|c|c|c} 
& Treinamento & Validação & Teste \\
\hline Experimento 1 & 122.4 & 90.8 & 110.4 \\
\hline Experimento 2 & 121.3 & 93.3 & 109.6 \\
\hline Experimento 3A & 65.7 & 61.3 & 62.9 \\
\hline Experimento 3B & 65.7 & 61.3 & 143.6 \\
\hline Experimento 3C & 65.7 & 61.3 & 90.9 \\
\hline
\end{tabular}

precipitação minimizou consideravelmente a superestimativa da projeção do ETA, principalmente no período de verão.

Nas Figuras 3 e 4 podem ser visualizados os hidrogramas da vazão observada média semanal, respectivamente, nos anos de 2002 e 2003, resultantes das simulações dos experimentos 1, 2 e 3 (A, B e $\mathrm{C})$, durante o período de teste. Nota-se que os hidrogramas referentes aos experimentos 1 e 2 não conseguem reproduzir os maiores picos de cheia, como pode ser observado tanto na semana 5 quanto na semana 49 do primeiro ano, e nas semanas 3, 9 e 47 do segundo ano (Figura 4). Nesses experimentos ficou clara a presença do efeito sombra na maior parte das ascensões e picos de cheias do hidrograma.

Tabela 3 - Erros absolutos médios na semana operativa $\left(\mathrm{m}^{3} \cdot \mathrm{s}^{-1}\right)$ no período de (2002 a 2003).

\begin{tabular}{l|c|c|c} 
& Treinamento & Validação & Teste \\
\hline Experimento 1 & 20.6 & 28.8 & 23.0 \\
\hline Experimento 2 & 20.4 & 29.3 & 23.1 \\
\hline Experimento 3A & 11.9 & 18.3 & 13.3 \\
\hline Experimento 3B & 11.9 & 18.3 & 28.5 \\
\hline Experimento 3C & 11.9 & 18.3 & 17.2 \\
\hline
\end{tabular}

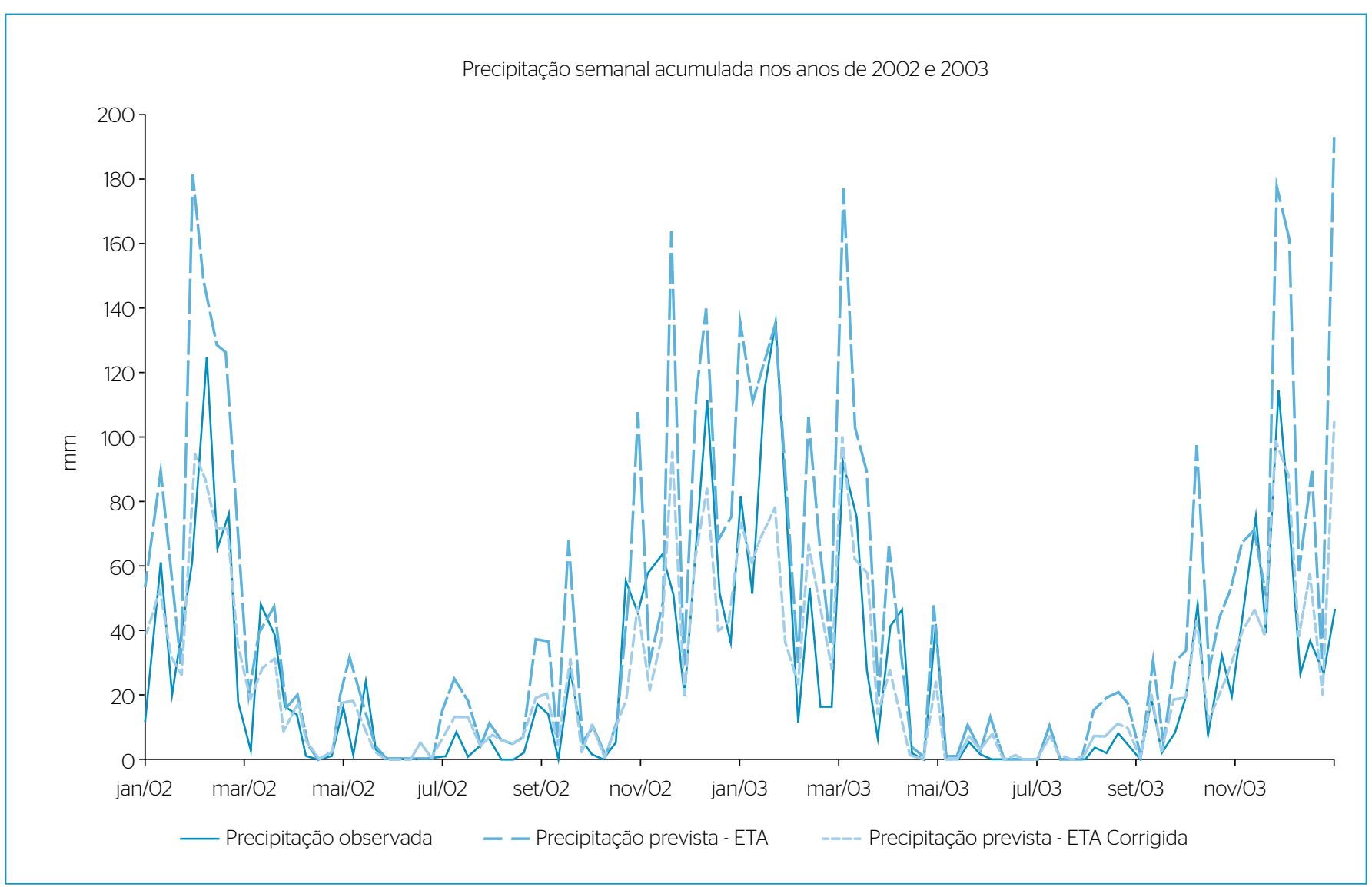

Figura 2 - Evolução temporal da precipitação semanal observada, prevista pelo modelo ETA e prevista pelo modelo ETA pós-processada com tratamento de redes neurais no trecho incremental da Bacia do Rio Grande a montante de furnas no período de 2002 a 2003. 


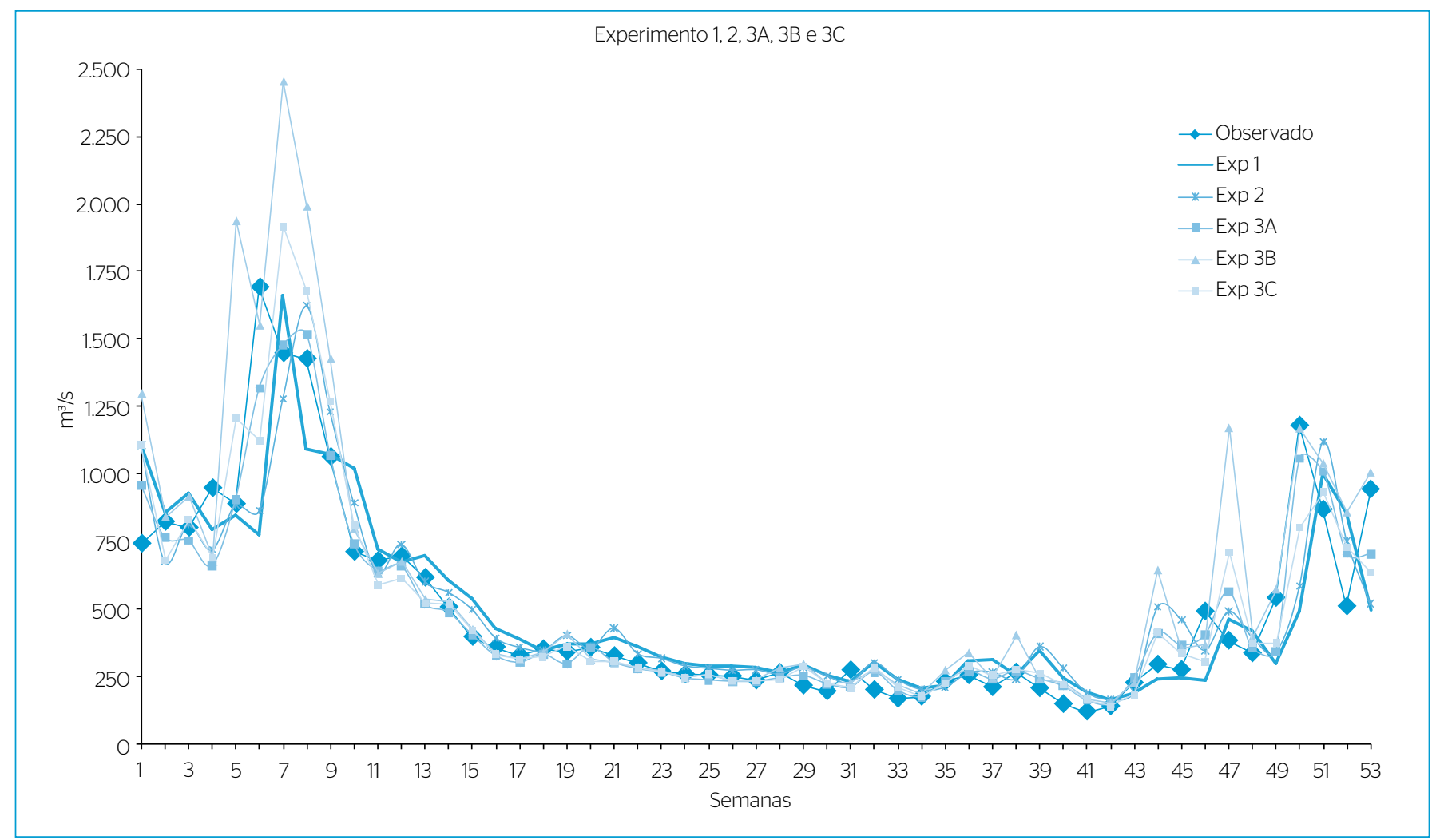

Figura 3 - Hidrograma dos experimentos 1, 2 e 3 para a fase de teste (2002).

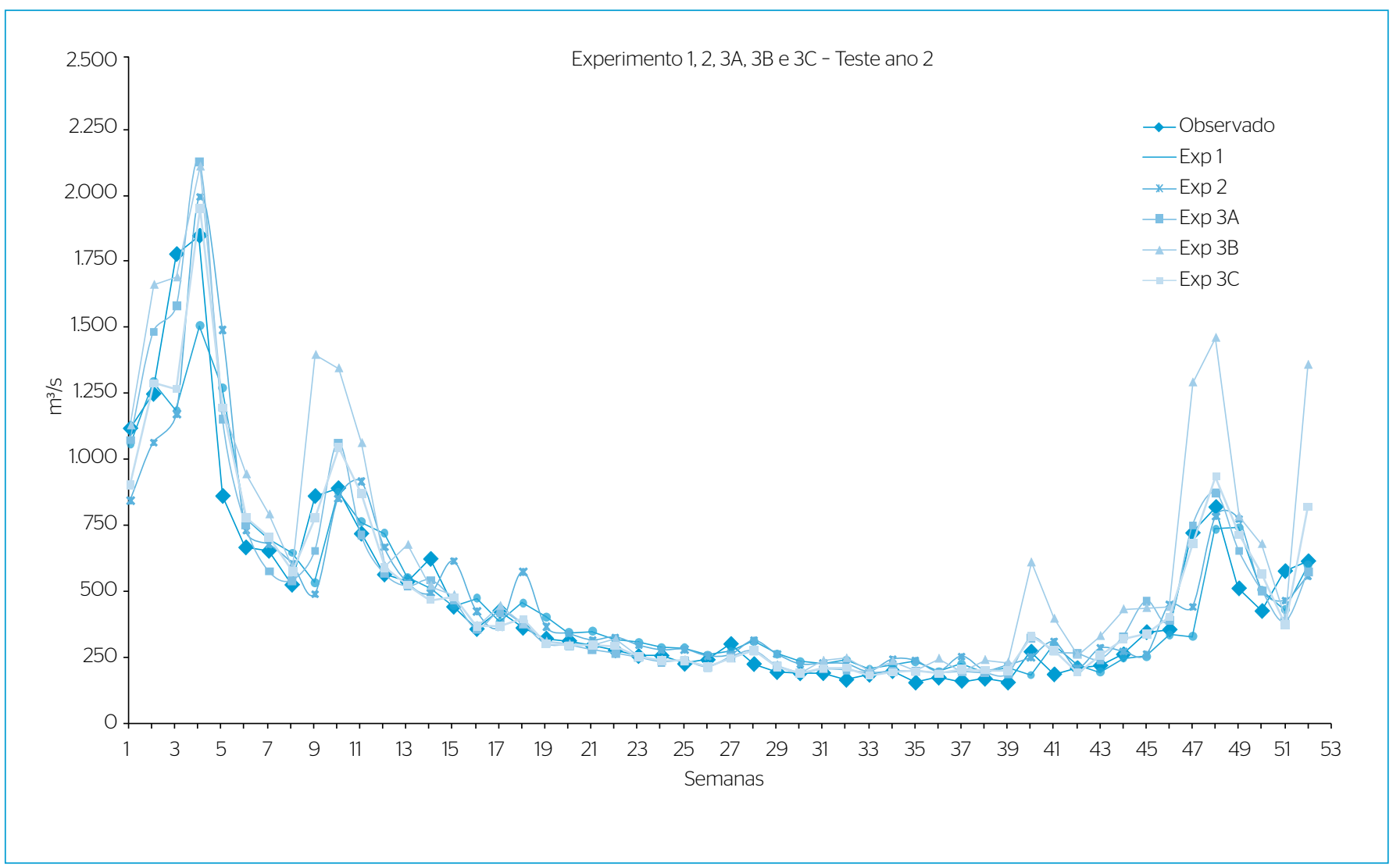

Figura 4 - Hidrograma dos experimentos 1, 2 e 3 para a fase de teste (2003). 
Esses dois experimentos também não representaram corretamente os períodos de recessão, com o hidrograma das previsões ficando sempre acima do com os valores observados, como pode ser verificado entre as semanas 21 e 28 do primeiro ano (Figura 3) e entre as semanas 20 e 37 do segundo ano (Figura 4).

O hidrograma referente às simulações do experimento $3 \mathrm{~A}$, nos dois anos de teste, foi o que melhor representou a dinâmica do comportamento hidrológico da bacia tanto nos períodos de ascensão e cheia, quando nos períodos de recessão. Observa-se que no experimento $3 \mathrm{~B}$ o hidrograma superestima o observado em quase todas as ascensões e cheias, como nas semanas $8,38,44$ e 46 no primeiro ano e 3, 10, 40, 48 e 52 no segundo ano. Nota-se também que nesse experimento foram mais bem capturados os períodos de recessão. O experimento $3 \mathrm{C}$ apresenta em sua configuração a correção da precipitação do modelo ETA. Com isso, foi possível perceber que, durante os períodos de cheia e ascensão, foram minimizadas as superestimativas do experimento $3 \mathrm{~B}$, apresentando resultados mais próximos do observado.

Verifica-se que a inclusão da precipitação prevista, independente da sua origem, proporcionou melhorias nas simulações dos períodos de recessão, inclusive no experimento $3 \mathrm{~B}$, no qual a precipitação prevista pelo modelo ETA não sofreu correção. Isso indica que a previsão de precipitação do modelo ETA é bastante eficiente para simular situações de ausência ou de totais muito pequenos de precipitação.

\section{CONCLUSÕES}

A elaboração deste estudo surgiu da necessidade constante de se realizar melhoras nas previsões de vazões, que são utilizadas, por exemplo, no planejamento hidroenergético da operação do SIN. Neste trabalho foi investigado o potencial da inclusão de informações de precipitação, tanto observada como prevista, no aperfeiçoamento dessas previsões.

Uma característica observada nos resultados de todos os experimentos, envolvendo diferentes configurações dos dados de entrada, foi o aumento no ERM e no EAM à medida que as previsões se afastavam das condições iniciais. Isso foi sentido em menor grau somente no experimento que utilizou a previsão de precipitação "perfeita", ou seja, a precipitação observada no horizonte temporal da precipitação prevista.

Ao incluir informações de precipitação passada na RNA (experimento 2) não foram observadas melhorias na qualidade da previsão que utilizava somente a vazão passada como dado de entrada (experimento 1) e, em alguns casos, até foram observados EAM maiores. Esse resultado pode estar relacionado ao fato da bacia possuir resposta rápida da vazão em relação à precipitação, com tempo de viagem inferior a um dia. Sendo assim, somente com esses dados não seria possível prever com precisão a variabilidade futura da vazão no trecho da bacia. Nessas simulações, utilizando somente informações de vazão passada e/ou informações de vazão e precipitação passadas, foram observados muitos casos de efeito "sombra", o que significa que o hidrograma dessas projeções, na maior parte dos casos, representou com defasagem de uma semana os picos de cheia e as recessões observadas.

A seguir, foram incluídos dados de chuva observada no horizonte temporal da previsão de chuva, o que pôde proporcionar resultados de base de uma predição "perfeita", seguindo a ideia de uma simulação "ideal" (experimento 3A). Esses foram os melhores resultados de todos os experimentos, como era de se esperar. Tanto os ERM como os EAM desse experimento foram consequência das imperfeições na modelagem matemática da RNA, da representação espacial da chuva e das medições de vazões passadas, não estando "contaminados" pelos erros de previsões de precipitação oriundas de modelagem matemática. No entanto, o experimento não traz uma condição realística para a utilização dessa modelagem em condições reais, nas quais a chuva futura não é conhecida, sendo necessária a estimativa dessa projeção a partir da utilização de modelos numéricos de previsão do tempo.

Sendo assim, foi substituído o conjunto de dados de testes do experimento $3 \mathrm{~A}$, incluindo-se a previsão de precipitação para oito dias a frente, obtida a partir de simulações do modelo ETA (experimento 3B). Verificou-se que, com a inclusão da previsão desse modelo, ocorreu um aumento nos ERM e EAM em relação aos experimentos anteriores, inclusive aqueles que utilizaram somente informações de vazão e chuva passados como dado de entrada. No entanto, observou-se nesse experimento que a maioria das simulações representou bem a variabilidade dos dados observados de vazão, inclusive nos períodos de cheia. Contudo, a inclusão da previsão do modelo ETA como insumo da RNA apresentou, de uma maneira geral, uma grande diminuição nos casos de efeito "sombra", muito comuns nas previsões estocásticas vazão-vazão, e uma melhora também nos períodos de recessão.

Por fim, foi realizado um novo experimento substituindo, no conjunto de testes, a previsão de precipitação do modelo ETA pela mesma previsão corrigida. Verificou-se que os resultados dessas simulações (experimento 3C) tiveram um desempenho melhor do que os encontrados nos experimentos 1, 2 e 3B, perdendo em desempenho somente para o experimento $3 \mathrm{~A}$.

Uma das conclusões deste trabalho é que, para a utilização das previsões de precipitação do modelo ETA na modelagem chuva-vazão, oiti dias a frente, é necessário, pelo menos para a Bacia do Rio Grande, um tratamento prévio dos resultados dessas previsões, seja ele estatístico ou baseado em técnicas de RNA.

Por fim, observou-se que os erros obtidos com a utilização da metodologia proposta neste estudo foram comparáveis aos de modelos conceituais, que normalmente necessitam de um período para calibração de cerca de três meses de ajustes às condições iniciais das variáveis de estado a cada interação, o que demanda recursos de algoritmos de otimização, além de uma grande quantidade de dias de precipitação observada. Para o ajuste do modelo de melhor 
configuração encontrada neste estudo (experimento 3C), o tempo de investigação foi menor, além de ser utilizada nessa modelagem somente um dia de precipitação observada. Sendo assim, entende-seque esse modelo se apresenta como uma ferramenta de grande utilidade na previsão de vazões, podendo ser calibrado e configurado em poucas semanas, com uma pequena variedade de dados de entrada, e sendo, portanto, replicável facilmente para quaisquer outras bacias do SIN.

\section{REFERÊNCIAS}

BAZARTSEREN, B.; HILDEBRANDT, G.; HOLZ, K.P. (2003) Short-term water level pre-diction using neural networks and neuro-fuzzy approach. Neurocomputing, v. 55, n. 2, p. 439-450.

BLACK, T.L. (1994) The new NMC mesoscale ETA model: description ad forecast examples. Weather and Forecasting, v. 9, p. 265-278.

CATALDI, M.; MACHADO, C.O;; GUILHON, L.G.F.; CHOU, S.C.; GOMES, J.L.; BUSTAMANTE, J.F. (2007a) Análise de previsões de precipitação obtidas com a utilização do modelo ETA como insumo para modelos de previsão semanal de vazão natural. Revista Brasileira de Recursos Hidricos, v. 12, n. 3, p. 5-12.

CATALDI, M.; MACHADO, B.G.F; DA SILVA, S.B.; GUILHON, L.G.F.; ACHÃO, C.C.L. (2007b) Aplicação de técnica de mineração de dados como complemento às previsões estocásticas univariadas de vazão natural: estudo de caso para a Bacia do Rio Iguaçu. Revista Brasileira de Recursos Hídricos, v. 12, n. 3, p. 83-92.

EVSUKOFF, A.G.; CATALDI, M.; DE LIMA, B.S.L.P (2012) A multi-model approach for long-term runoff modeling using rainfall forecasts. Expert Systems with Applications, v. 39, n. 5, p. 4938-4946.

FERNÁNDEZ BOU, A.S.; VENTURA DE SÁ, R.; CATALDI, M. (2015) Flood forecasting in the upper Uruguay River basin. Natural Hazards, v. 79, n. 2, p 1239-1256.

GOMES, L.F.C. (2006) Previsão de vazões naturais diárias ao reservatório de três marias usando a técnica de redes neurais. Dissertação (Mestrado) - Universidade Federal de Pernambuco, Recife.

GOUTTE, C. (1997) Statistical learning and regularization for regression: application to system identification and time series modelling. Tese (Pós-doutorado) - Université Paris 6, Paris.

GUILHON, L.G.F. (2002) Modelo heurístico de previsão de vazões naturais médias semanais aplicado à usina de foz do areia. Dissertação (Mestrado) - Universidade Federal do Rio de Janeiro, Rio de Janeiro.
GUILHON, L.G.F.; ROCHA, V.F.; MOREIRA, J.C. (2007) Comparação de métodos de previsão de vazões naturais afluentes a aproveitamentos hidroelétricos. Revista Brasileira de Recursos Hídricos, v. 12, n. 3, p. 13-20.

GUYON, I. \& ELISSEEFF, A. (2003) An introduction to variable and feature selection, Journal of Machine Learning Research, v. 3, p. 1157-1182.

HAYKIN, S.O. (2008) Neural networks and learning machines. 3 ed. New Jersey: Prentice Hall. 906 p.

HEATH, M.T. (2002) Scientific computing: an introductory survey, New York: McGraw Hill. p. 563 e xii.

HIDROWEB [homepage da internet]. (2016) Hidroweb. Disponível em: http://hidroweb.ana.gov.br/default.asp. Acesso em: 15 abr. 2013.

MAIER, H.R. \& DANDY, G.C. (2000) Neural networks for the prediction and forecasting of water resources variables: a review of modelling issues and applications. Environmental Modelling \& Software, v. 15, n. 1, p. 101-124.

MESINGER, F.; JANJIĆ, Z.I; NIKOVIĆ, S.; GAVRILOV, D.; DEAVEN, D.G. (1988) The step-mountain coordinate: model description description and performance for cases of Alpine lee cyclogenesis and for a case of Appalachian redevelopment. Monthly Weather Review, v. 116, p. 1493-1518.

OLIVEIRA, S.L.; CATALDI, M.; TORRES JÚNIOR, A.R. (2008) Avaliação climatológica da distribuição média mensal de precipitação em bacias hidrográficas integrantes do SIN, utilizando os dados do CRU. In: /I Simpósio de Recursos Hídricos do Sul-Sudeste. Anais.... Rio de Janeiro.

SATURNINO BRAGA, R.; CATALDI, M.; CRETON DE OLIVEIRA, H. (2009) Metodologia para previsão de vazões na bacia do rio Rio Grande. In: XVIII Simpósio Brasileiro de Recursos Hidricos. Anais.. Campo Grande.

VALENÇA, M.J.S. (2005) Aplicando redes neurais: um guia completo. Editora Livro rápido. Olinda: Ed. do Autor. 284 p. 